\title{
Karayolu Kenarındaki Heyelan Bölgesinin Bazı Toprak Özelliklerinin Belirlenmesi: Lapseki-Şevketiye (Çanakkale) Örnek Çalışması
}

\author{
Mehmet Parlak ${ }^{1, *}$ (i) \\ ${ }^{1}$ Çanakkale Onsekiz Mart Üniversitesi Lapseki Meslek Yüksekokulu,17800, Lapseki-Çanakkale.

\section{Özet}

Heyelanlar önemli çevre sorunları ortaya çıkarmaktadırlar. Karayolu kenarındaki heyelanlar doğal bir olay olup dik ĕ̆im, yağış ve toprak özelliklerinin etkisiyle oluşurlar. Heyelanların neden olduğu çevre sorunlarından birisi de verimli üst toprağın kaybını takiben alanın verimliliğinin azalarak arazi bozulmasının görülebilmesidir. Bu araştırma Çanakkale-Bursa karayolu kenarındaki bir heyelanın (Şevketiye) içinden ve buğday tarlasından alınan toprakların $(0-10 \mathrm{~cm}$ derinlik) bazı özelliklerini ( $\mathrm{pH}$, elektriksel iletkenlik, kireç, organik madde, toplam azot $(N)$, alınabilir fosfor $(P)$, alınabilir potasyum $(K)$, tekstür, agregat stabilitesi, likit limit, plastik limit, plastiklik indeksi ve kil aktivitesi) karşılaştırmak için yapılmışır. Toprak özelliklerinin karşılaşstırlmasında t testi kullanılmıștır. Heyelanın içinden alınanlara göre buğday tarlasından alınan toprak örneklerinde elektriksel iletkenlik (EC), organik madde, alınabilir potasyum (K), kil, silt ve plastiklik indeksi yüksek; pH ve ince kum miktarları ise daha düşük saptanmıştır. Kireç, toplam azot $(N)$, alınabilir fosfor $(P)$, kaba kum, likit limit, plastik limit ve kil aktivitesi bakımından istatistik olarak önemli farklılıklar saptanmamıştır. Toprak özelliklerini iyileştirmek için heyelandan etkilenen alanlara hayvan gübresi, hasat artıkları veya kompost uygulanmalıdır.

\section{Anahtar Sözcükler}

Heyelan, Toprak Verimliliği, Atterberg Limitleri, Karayolu, Çanakkale

\section{Determination of Some Soil Characteristics of Roadside Landslides Region: A Case Study of Lapseki-Sevketiye (Çanakkale)}

\begin{abstract}
Landslides bring about serious environmental problems. Roadside landslides are a common natural phenomenon. They are often triggered by a combination of steep relief, rainfall and soil properties. The loss of upper fertile soil layer is among the most significant environmental problems induced by landslides. Such losses lead to land degradation. This study was conducted to compare some characteristics ( $\mathrm{pH}$, electrical conductivity, lime, organic matter, total nitrogen ( $N)$, available phosphorus $(P)$, available potassium $(K)$, texture, aggregate stability, liquid limit, plastic limit, plasticity index, and clay activity) of the soils (0-10 cm depth) taken from inside and wheat field of a landslide occurred at the side of Çanakkale-Bursa highway (around Sevketiye section). In comparison of soil properties the paired t test was used. While wheat field samples had higher electrical conductivity, organic matter, available potassium $(K)$, clay, silt, and plasticity index, but lower $p H$ and fine sand contents than the inside samples. Statistically significant differences were not observed in terms of lime, total nitrogen $(N)$, available phosphorus $(P)$, available potassium $(K)$, coarse sand, liquid limit, plastic limit, plasticity index and clay activity. Farmyard manure, harvest residues or compost can be applied to improve soil characteristics in landslide-influenced areas.
\end{abstract}

Keywords

Landslide, Soil Fertility, Atterberg Limits, Highway, Çanakkale

\section{Giriş}

Heyelan kum ve çakıl gibi gevşek kütlelerin ve tabakalı tortul arazilerin doğal dengenin bozulduğu yerlerde yerçekiminin etkisiyle kütle halinde kayması olayıdır. Heyelanı, diğer kütle hareketinden ayıran en öneli fark, büyük kütlenin üzerindeki bina, yol, ağaç vb. ile birlikte aniden kaymasıdır. Heyelan eden muazzam miktardaki kütlenin yı̆̆ıldığı vadi, yamaç eteklerinde de büyük tahribat oluşmakta; buralardaki yerleşme, yol ve köprüler tahrip olmaktadır (Atalay 2016). Jeolojik yapı, topoğrafya, toprak, yağış ve insan aktivitelerinin heyelan oluşumuna katkıda bulundukları bilinmektedir. Ülkemiz, jeolojik, jeomorfolojik yapısı ve sahip olduğu iklim özellikleri nedeniyle can ve mal kaybına yol açan heyelanlarla sık sık karşılaşmaktadır. Türkiye' de son 50 yılda 13494 heyelan kaydedilmiş ve bu doğal afetten etkilenen insan sayısı toplamda 59345 kişidir (Gökçe vd. 2008). 
Çanakkale heyelanlar bakımından hem olay sayısı hem de olaylardan etkilenen afetzede sayısı bakımından şanslı illerden biri olsa da jeolojik özellikleri dikkate alındığında heyelan risk potansiyelinin yüksek olduğu görülmektedir. Çanakkale yakın çevresinde çok sayıda aktif ve pasif (fosil) heyelan bulunmaktadır. Biga yarımadasında toplam alanı $93862 \mathrm{~m}^{2}$ olan 731 adet heyelan haritalanmıştır. Bu heyelanlardan $56559 \mathrm{~km}^{2}$ alan kaplayan 249 adedi eski-derin, 30 $078 \mathrm{~km}^{2}$ alan kaplayan 457 adedi aktif-derin ve $7225 \mathrm{~km}^{2}$ alan kaplayan 25 adedi de aktif-sığ heyelandır (Yiğitbaş 2016).

Karayollarındaki heyelanların ana nedenleri; ülkemizin olumsuz jeolojik yapısı, aktif deprem kuşakları içerisinde yer alması, morfolojik yapıya bağlı olarak yüksek dağlık alanlar ile geçit noktaları içermesi, ülke genelinde yamaç eğimlerinin yüksek olması olarak sıralanabilir. Bu faktörlere bağlı olarak, olumsuz meteorolojik faktörlerin etkisiyle heyelanlar gelişebilmekte ve trafik güvenliği olumsuz etkilenmektedir (Anaçali ve Şirin 2015). Karayollarında yol genişletme ve yol yapım çalışmaları da heyelanları tetiklemektedir. Karayollarındaki heyelanlar nedeniyle ulaşım hatlarının servise kapanmasıyla ürünlerin ve hammaddelerin zamanında yerine ulaştırılamamasından kaynaklanan kayıplar da görülebilmektedir. Aynı zamanda, heyelanlar karayolundaki restorasyon masraflarını da önemli ölçüde artırmaktadırlar.

Heyelan oluşumu toprağın fiziksel ve kimyasal özelliklerini etkilemektedir. Heyelanlar yüzey toprağının kaybına ve toprak profilinin alt üst olmasına neden olurlar. Cheng vd. (2016) heyelanların topraktaki O ve A horizonunun kalınlığını ve organik karbonu azaltırken, toprağın pH'sını artırdığını saptamışlardır. Hacısalihoğlu vd. (2018) Rize' de heyelan alanları ile yanındaki bozulmamış alanlardan aldıkları toprak örneklerinin hidrolik iletkenlik, hacim ağırlığı, $\mathrm{pH}$ ve organik madde kapsamlarının farklılık gösterdiğini bildirmişlerdir. Wilcke vd. (2003) heyelan alanında üst toprağın verimliliğinin azaldığını saptamışlardır. Toprak organik maddesi ve besin maddeleri $(\mathrm{Ca}, \mathrm{Mg}, \mathrm{P}, \mathrm{K})$ heyelan alanına göre bitişiğindeki alanda genellikle daha yüksek bulunmuştur (Dalling ve Tanner 1995). Basher vd. (2018) yaptıkları araştırmada heyelanların toprak karbon stoklarını azalttığını bildirmişlerdir. Simon vd. (2017) Malezya'da RanauTambunan karayolu boyunca heyelan olan ve olmayan alanlardan aldıkları toprak örneklerinin tane büyüklüğü dağılımlarının birbirinden farklı olduğunu belirtmişlerdir.

Ülkemizde karayolu kenarlarındaki heyelanların oluşumuna etki eden faktörlerle ilgili araştırmalar (Ertek vd. 1993; Yılmaz ve Karacan 2002; Keser 2003; Erginal ve Bayrakdar 2006; Ataol ve Yeşilyurt 2014; Perinçek 2018) yapılmasına rağmen karayolu çevresindeki heyelanların toprak özelliklerine etkisini inceleyen araştırmaya rastlanılmamıştır. $\mathrm{Bu}$ araştırmanın amacı karayolu kenarındaki heyelanın içinden ve dışından (buğday tarlasından) alınan toprak örneklerinin bazı kimyasal, fiziksel ve mekaniksel özelliklerini karşılaştırmaktır.

\section{Materyal ve Yöntem}

\section{1. Çalışma Alanı}

Çalışma alanı, Çanakkale-Bursa karayolu üzerinde olup, Şevketiye Köyü (Çanakkale ili Lapseki ilçesi) sınırları

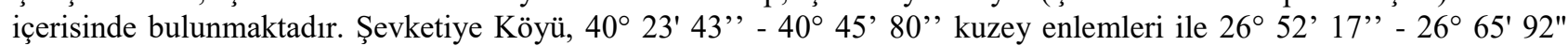
doğu boylamları arasında kalmaktadır. Şevketiye Köyü, Çanakkale şehir merkezine 48 km, Lapseki ilçe merkezine ise 17 km uzaklıktadır. Biga yarımadası'nda bulunan çalışma alanının jeolojisi eosen-miyosen yaştaki Fıçıdere formasyonu olarak adlandırılan denizel sedimentlerden oluşmaktadır (Ercan vd. 1995). Çalışma alanı içerisinde heyelan alanı ve buğday tarlası mevcuttur (Şekil 1). Heyelan alanı ile buğday tarlası arasındaki mesafe 50 m'dir. Heyelan alanı 11.670 $\mathrm{m}^{2}$, buğday tarlası ise $4600 \mathrm{~m}^{2}$ alana sahiptir. Heyelan alanı ve buğday tarlasının ortalama eğimleri sırasıyla \%32 ve \%5'dir. Çalışma alanı Marmara geçiş iklimi etkisi altındadır. Lapseki'de meteoroloji istasyonu bulunmadığından Çanakkale'deki meteoroloji istasyonunun verileri kullanılmıştır. Meteorolojik verilere (1975-2015) göre Çanakkale'nin ortalama yıllık yağış miktarı $514 \mathrm{~mm}$, ortalama y1llık sıcaklığı ise $11.4^{\circ} \mathrm{C}$ 'dir (URL-1 2016). Şevketiye köyündeki heyelan sığ dönel (rotasyonel) heyelandır. Çalışma alanındaki ana materyal konglomera olup vejetasyonda ise kermes meşesi (Quercus coccifera), katırtırnağı (Spartium junceum), böğürtlen (Rubus fructicosus), abdest bozan(Sarcopoterium spinosum) ve domuz ayrığı (Dactylis glomerata) mevcuttur. Heyelan alanının toprak derinliği 20 $30 \mathrm{~cm}$, buğday tarlasındaki toprak derinliği ise $60 \mathrm{~cm}$ 'dir. 


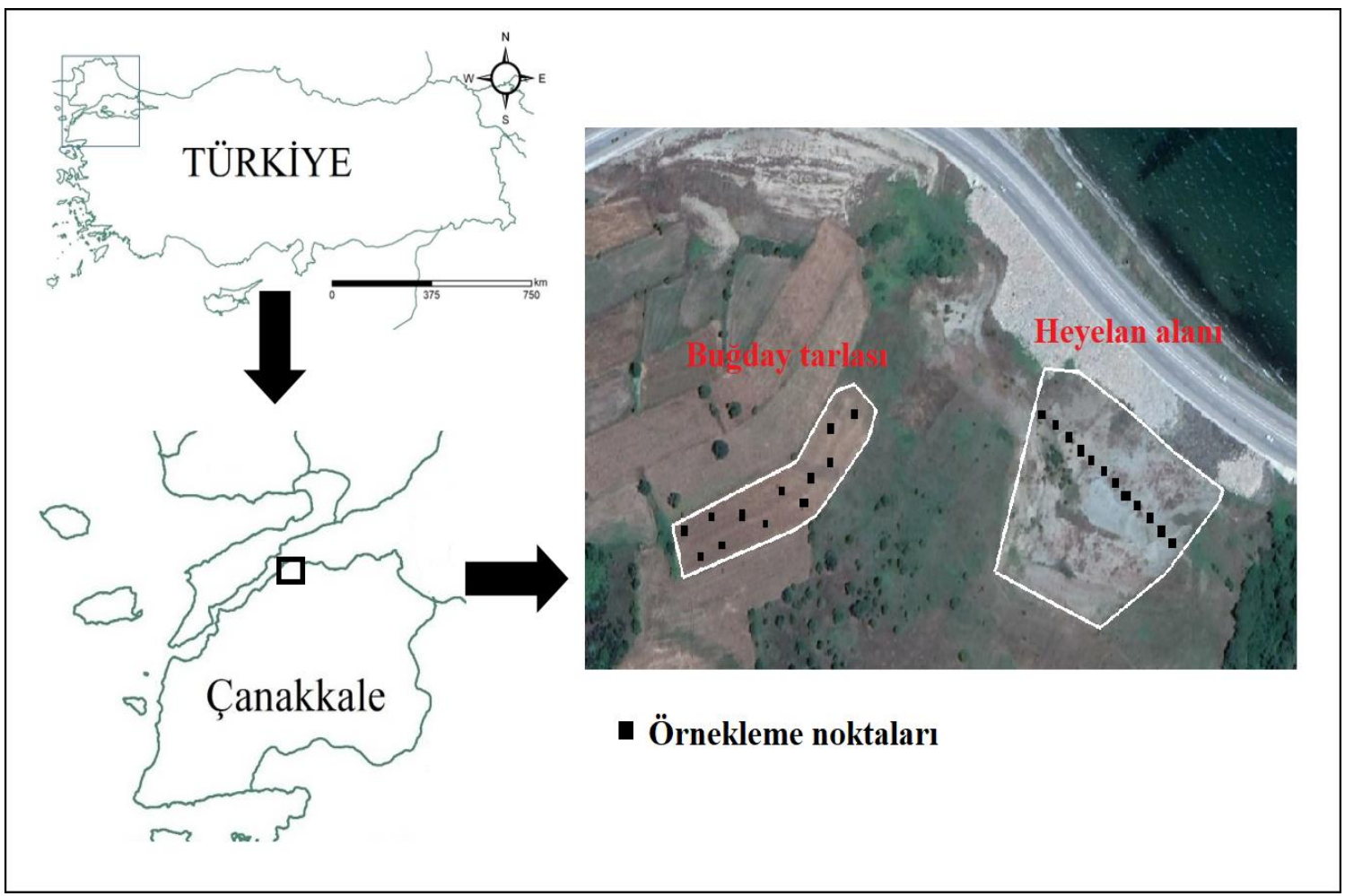

Şekil 1: Çalışma alanının konumu

\subsection{Toprak Örneklerinin Alınması}

Heyelan içi toprak örnekleri heyelanın aşınma ve birikme bölgeleri arasındaki bölgeden bir hat boyunca ve eş yükselti eğrisine paralel olacak şekilde $0-10 \mathrm{~cm}$ derinlikten 12 noktadan alınmıştır. Her toprak örneği 3 alt örneğin birleşmesinden oluşmuştur. Heyelanın dişındaki buğday tarlasından rastgele örnekleme yöntemine göre 0-10 cm derinlikten 3 toprak örneği alınarak karıştırılmış ve tek örnek yapılarak 12 toprak örneği alınmıştır. Alınan toprak örnekleri laboratuvar ortamında kurutularak ve tahta tokmak kullanılarak 2 mm'lik elekten elenmiş, analizlere hazır hale getirilmiştir.

\subsection{Toprak Analizleri}

pH ve elektriksel iletkenlik (EC): saturasyon çamurunda cam elektrotlu pH metre (McLean 1982) ve EC metreyle (Rhoades 1982); kireç toprağın $\mathrm{HCl}$ ile tepkimesi sonucunda açığa çıkan $\mathrm{CO}_{2}$ gazının kalsimetrede ölçülmesiyle (Nelson 1982); organik madde değiştirilmiş Walkley-Black metoduyla (Nelson ve Sommers 1982); toplam N (azot) Kjehdal cihazında Bremner (1996) metoduyla; alınabilir P (fosfor) Olsen ve Sommers (1982) metoduyla; alınabilir K (potasyum) alev fotometre kullanılarak Kenudsen vd. (1982) metoduyla; bünye (kil, silt, ince kum ve kaba kum) Gee ve Bauder (1986) metoduyla; agregat stabilitesi mikro agregatlarda $(<0.25 \mathrm{~mm})$ Yoder tipi 1slak eleme aletinde (Nimmo ve Perkins 2002); likit limit Casagrande aletiyle (McBride 1993); plastik limit ise nemli toprağın 2-3 mm çapında iplik haline getirilmesinden sonra dağılmaya başladığı anda sahip olduğu nem miktarına göre belirlenmiştir (McBride 1993). Plastiklik indeksi, likit limitten plastik limitin çıkarılmasıyla (Baumgartl 2002); kil aktivitesi ise plastiklik indeksinin kil içeriğine bölünmesiyle hesaplanmıştır (Baumgartl 2002).

\section{4. İstatistik Analiz}

Heyelan alanının içinden ve buğday tarlasından alınan toprakların özelliklerinin karşılaştırılması normal dağılım gösterenlerde $\mathrm{t}$ testi, normal dağılım göstermeyenlerde ise Mann-Whitney $U$ testi kullanılarak yapıllmıştır. İstatistik analizler SPSS Statistical Package v.20.0 (IBM 2011) yardımıyla saptanmıştır.

\section{Bulgular ve Tartışma}

Heyelanın içinden ve buğday tarlasından alınan toprak örneklerinin pH, EC, organik madde, alınabilir K, kil, silt, ince kum ve plastiklik indeksinde önemli farklılıklar saptanırken; kireç, toplam N, alınabilir P, kaba kum, likit limit, plastik limit ve kil aktivitesi bakımından farklılıklar belirlenememiştir (Tablo 1). 
Bazı toprak özelliklerindeki (alınabilir K, kil, silt, ince kum, kaba kum ve agregat stabilitesi) standart sapmanın yüksek olması, değerler arasındaki farkın yüksek olduğunu ve grubun heterojen olduğunu göstermektedir. Heyelanın içinde ve buğday tarlasındaki alanda Atterberg limitleri (likit limit, plastik limit) bakımından istatistiksel açıdan bir fark çıkmasa da Atterberg limitleri toprak özellikleri ile ilişkilidir (Baumgartl 2002). Atterberg limitleri toprak su potansiyelini yansıtır ve toprak bünyesi ile toprağın su tutulma enerjisine bağlıdır. Aynı zamanda kil aktivitesi 0,75 'den küçük olduğu için heyelan alanındaki killer çok az şişme büzülme özelliği gösteren inaktif kil grubuna girmektedirler.

Tablo 1: Heyelanın içinden ve buğday tarlasından alınan toprak örneklerinin bazı özellikleri (Ortalama \pm standart sapma $)^{*}(n=24)$

\begin{tabular}{|c|c|c|c|}
\hline Özellik & Heyelan içi & Buğday tarlası & $\mathrm{p}$ değeri \\
\hline $\mathrm{pH}$ & $7.68 \pm 0.12 \mathbf{a}$ & $7.59 \pm 0.04 \mathbf{b}$ & 0.0012 \\
\hline $\mathrm{EC}\left(\mathrm{dS} \mathrm{m} \mathrm{m}^{-1}\right)$ & $0.52 \pm 0.12 \mathbf{b}$ & $0.71 \pm 0.06 \mathbf{a}$ & 0.0000 \\
\hline Kireç (\%) & $3.96 \pm 1.97$ & $2.99 \pm 0.98$ & 0.1450 \\
\hline Organik madde $(\%)$ & $1.08 \pm 0.02 \mathbf{b}$ & $1.14 \pm 0.05 \mathbf{a}$ & 0.0111 \\
\hline Toplam azot (\%) & $0.052 \pm 0.01$ & $0.056 \pm 0.02$ & 0.5444 \\
\hline Alınabilir P $\left(\mathrm{mg} \mathrm{kg}^{-1}\right)$ & $7.02 \pm 2.11$ & $8.44 \pm 1.54$ & 0.0999 \\
\hline Alınabilir K (mg kg-1) & $38.85 \pm 16.54 \mathbf{b}$ & $67.08 \pm 6.13 \mathbf{a}$ & 0.0002 \\
\hline Kil (\%) & $6.52 \pm 4.03 \mathbf{b}$ & $12.18 \pm 3.09 \mathbf{a}$ & 0.0018 \\
\hline Silt $(\%)$ & $16.60 \pm 12.13 \mathbf{b}$ & $34.46 \pm 5.07 \mathbf{a}$ & 0.0014 \\
\hline İnce kum (\%) & $72.18 \pm 16.08 \mathbf{a}$ & $47.59 \pm 6.17 \mathbf{b}$ & 0.0014 \\
\hline Kaba kum (\%) & $4.70 \pm 1.94$ & $5.77 \pm 2.43$ & 0.3123 \\
\hline Agregat stabilitesi (\%) & $75.70 \pm 18.50$ & $78.00 \pm 15.40$ & 0.7410 \\
\hline Likit limit (\%) & $23.94 \pm 4.32$ & $25.82 \pm 4.65$ & 0.3150 \\
\hline Plastik limit (\%) & $21.20 \pm 3.11$ & $22.85 \pm 1.37$ & 0.1120 \\
\hline Plastiklik indeksi & $2.74 \pm 1.58 \mathbf{b}$ & $4.63 \pm 2.59 \mathbf{a}$ & 0.0440 \\
\hline Kil aktivitesi & $0.53 \pm 0.34$ & $0.41 \pm 0.28$ & 0.3560 \\
\hline
\end{tabular}

Heyelanın dışındaki buğday tarlasından alınan topraklarda pH'nın daha düşük olma nedeni bitki kökleri tarafından rizosfere salgılanan organik asitler ve hidrojen iyonlarının toprak pH'sını düşürmeleridir (Marschner 2012; Schomakers vd. 2017). Çalışma alanında herhangi bir tuzlanma sorunu (EC $<4 \mathrm{dS} \mathrm{m}^{-1}$ ) bulunmamakla birlikte heyelan dışındaki alanda toprağın elektriksel iletkenliğinin yüksek olması kimyasal gübreler ile ahır gübresinin kullanılmasıyla ilgilidir (Sönmez vd. 2008). Organik madde besin maddelerinin yarayışlılığını ve döngüsünü, rutubet kapsamını, pH'yı, mikroorganizmaların varlığı ile aktivitesini, diğer toprak faunasını etkilediği için belki de heyelandaki toprak özelliklerini belirleyen en önemli parametredir (Walker vd. 1996). Heyelanlar toprak bitki sistemlerinin tahrip olmasına neden olduklarından yüzey toprağındaki organik madde ve alınabilir besin maddesi miktarlarını azaltmaktadırlar. Örnekleme yapılan heyelanın dışındaki buğday tarlasında hasat artıklarının olması, ahır gübresi ile kimyasal gübrelerin kullanılması dolaylı olarak kök gelişimini etkilediği için toprak organik maddesi ve alınabilir K kapsamını artırmıştır. Heyelanda yüzey akışla besin maddesi (azot, fosfor, potasyum, kalsiyum) kayıpları heyelan yakınındaki bozulmamış alanlara göre daha çoktur (Walker ve Shiels 2012). Van Eynde vd. (2017) Uganda'daki Elgon Dağı'nın güneybatı kısmındaki heyelanlarda yaptıkları araştırmada; heyelanların içinden aldıklarına göre heyelanların dışındaki toprak örneklerinin organik karbon ve alınabilir K kapsamlarının daha yüksek olduğunu belirtmişlerdir. Heyelanın içinden alınan toprak örneklerinde bünye kumlu tın, tın, tınlı kum, kum iken buğday tarlasından alınanlarda ise kumlu tın ve tın olarak saptanmıştır (Tablo 1). Heyelan alanında toprak kayıplarının olması ve toprağın karışması araştırma alanındaki bünyelerin farklı olmasına neden olmuştur. Reddy ve Singh (1992) tahrip olmamış alana göre heyelandaki ince toprak kapsamı $(<0.2 \mathrm{~mm})$ ile besin maddelerini daha düşük saptamışlardır.

Heyelana neden olan etkenlerden (jeolojik, jeomorfolojik, fiziksel ve insanlardan kaynaklanan) eğimin araştırma alanında etkili olduğu söylenebilir. Toprak suyla doygun olduğunda eğimin etkisiyle heyelan meydana gelebilir. Knapen vd. (2006) heyelanların oluşmasında yağış, dik eğim ve eğim şeklinin etkili olduğunu bildirmişlerdir. Yalçın (2011) Trabzon'daki heyelanların yaklaşık \%31' inin \%30-50 eğim sınıfında oluştuğunu saptamıştır. Zhang vd. (2012) sı̆̆ heyelanların oluşmasında yağış ve topoğrafik değişkenlerin (yöney, eğim şekli, yükseklik ve eğim açısı) hakim faktörler olduğunu belirtmişlerdir. Coşkun vd. (2016) Çanakkale' de bir heyelan alanında yapmış oldukları araştırmada; eğim, aşırı yağış ve killi materyallerin etkisiyle heyelanın görüldüğünü saptamışlardır. Jacobs vd. (2017) sığ heyelanları belirleyen esas faktörlerin eğim dikliği ve litoloji olduğunu bildirmişlerdir. Xu vd. (2018) heyelanların oluşumunu etkileyen faktörlerin yağış, yükseklik, eğim ve litoloji olduğunu saptamışlardır. 


\section{Sonuçlar}

Heyelan alanından ve heyelanın dişındaki alandan (buğday tarlası) alınan toprak örneklerinin bazı kimyasal (pH, elektriksel iletkenlik, organik madde, alınabilir K), fiziksel (kil, silt, ince kum) ve mekaniksel (plastiklik indeksi) özellikleri farklılıklar göstermiştir. Toprak özelliklerinin farklılık göstermesinde eğimin etkisiyle heyelan etkili olmuştur. Heyelan alanında üst toprağın verimliliği azalır ve çevresindeki bozulmamış topraklara göre bitki gelişimi için daha az uygun koşullar oluşur. Heyelanın etkilediği alanlarda toprağın organik madde miktarını artıracak uygulamalar (ahır gübresi, kompost, hasat artıkları) yapılmalı, doğal vejetasyona uygun derin köklü bitkilerin yetiştirilmesine önem verilmeli ve mekaniksel tedbirlere de başvurulmalıdır.

\section{Kaynaklar}

Anaçali İ., Şirin A., (2015), Heyelan tanımlama ve veri oluşturma kılavuzu, T.C. Ulaştırma, Denizcilik ve Haberleşme Bakanlığı, Karayolları Genel Müdürlüğü, Araştırma ve Geliştirme Dairesi Başkanlığı, Jeolojik Hizmetler Şubesi Müdürlüğü, Ankara, 42 ss.

Atalay İ., (2016), Uygulamalı Jeomorfoloji, Meta Basım Matbaacılık Hizmetleri, İzmir, 488 ss.

Ataol M., Yeşilyurt S., (2014), Çankırı Ankara karayolu boyunca (Akyurt-Çankırı arası) heyelan risk bölgelerinin belirlenmesi, Coğrafya Dergisi, 29, 51-69.

Basher L., Betts H., Lynn I., Marden M., McNeill S., Page M., Rosser B., (2018), A preliminary assessment of the impact of landslide, earthflow, and gully erosion on soil carbon stocks in New Zealand, Geomorphology, 307, 93-106.

Baumgartl T., (2002), Atterberg limits, Encyclopedia of Soil Science'1n İçinde, (Lal R., Ed.), Marcel Dekker, Inc. ss. 89-93.

Bremner J.M., (1996), Nitrogen-Total, Methods of Soil Analysis'in İçinde, Part 3, Chemical Methods'un İçinde, (Sparks D.L., Ed.), ASA and SSSA, Madison, WI, SSSA Book Series. No: 5. ss. 1085-1122.

Cheng C.H., Hsiao S.C., Huang Y.S., Hung C.Y., Pai C.W., Chen C.P., Menyailo O.V., (2016), Landslide-induced changes of soil physicochemical properties in Xitou, Central Taiwan, Geoderma, 265, 187-195.

Coşkun N., Çakır Ö., Erduran M., Kutlu Y.A., Çetiner Z.S., (2016), A potential landslide area investigated by 2.5 D electrical resistivity tomography: Case study from Çanakkale, Turkey, Arabian Journal of Geosciences, doi: 10.1007/s12517-015-2026-x.

Dalling J.W., Tanner E.V.J., (1995), An experiment study of regeneration on landslides in montane rain forest in Jamaica, Journal of Ecology, 83, 55-64.

Ercan T., Satı M., Steinitzs G., Dora A., Sarıfakıoğlu E., Adis C., Walter H.J., Yıldırım T., (1995), Biga Yarımadası ile Gökçeada, Bozcada ve Tavşan Adaları' ndaki (KB Anadolu) tersiyer volkanizmasının özellikleri, MTA Dergisi, 117, 55-86.

Erginal A.E., Bayrakdar C., (2006), Karayolu heyelanlarına bir örnek: Inecik heyelanı (Tekirdağ). Coğrafya Dergisi, $14,43-53$.

Ertek T.A., Turoğlu H., Mater B., (1993), Çiftlik heyelanı (Sinop), Türk Coğrafya Dergisi, 28, 181-188.

Gee G.W., Bauder J.W., (1986), Particle-size analysis, Methods of Soil Analysis'in içinde, Part 1, Physical and Mineralogical Methods (Klute, A.,Ed.), ASA and SSSA, Madison, WI, USA, ss. 383-411.

Gökçe O., Özden Ş., Demir A., (2008), Türkiye'de afetlerin mekansal ve istatistiksel dağılımı afet bilgileri envanteri, Bayındırlık ve İskan Bakanlığı Afet İşleri Genel Müdürlüğü, Afet Etüt ve Hasar Tespit Daire Başkanlığı, Ankara, 118 ss.

Hacisalihoğlu S., Gumus S., Kezik U., (2018), Land use conservation effects triggered by tea plantation on landslide occurrence and soil loss in northeastern Anatolia, Turkey, Fresenious Environmental Bulletin, 27(5), 2933-2942.

IBM, (2011), IBM SPSS Statistics for Windows, Version 20.0. IBM Corporation, Armonk, New York.

Jacobs L., Dewitte O., Poesen J., Maes J., Mertens K., Sekajugo J., Kervyn M., (2017), Landslide characteristics and spatial distribution in the Rwenzori Mountains, Uganda, Journal of African Earth Sciences, 134, 917-930.

Kenudsen D., Peterson A., Pratt P.F., (1982), Lithium, sodium, and potassium, Methods of Soil Analysis'in İçinde, Part 2, Chemical and Microbiological Properties (Page A.L., Miller R.H., Keeney D.R., Eds.), ASA, SSSA, Agronomy No: 9. Madison, Wisconsin, USA, ss. 225-245.

Keser N., (2003), Kütahya'nın kuzeybatısında heyelan olayları, Türk Coğrafya Dergisi, 40, 99-120.

Knapen A., Kitutu M.G., Poesen J., Breugelmans W., Deckers J., Muwanga A., (2006), Landslides in a densely populated county at the footslopes of Mount Elgon (Uganda): Characteristics and causal factors, Geomorphology, 73, 149-165.

Marschner P., (2012), Marschner's mineral nutrition of higher plants. Third Edition, Academic Press, New York, USA, ss. 672.

McBride R.A., (1993), Soil consistency limits, Soil Sampling and Methods of Analysis'in İçinde, (Carter, M.R., Ed.), Lewis Publication, CRC Press, Boca Raton, FL, ss. 519-527.

McLean E.O., (1982), Soil pH and lime requirement, Methods of Soil Analysis'in İçinde, Part 2, Chemical and Microbiological Properties (Page A.L., Miller R.H., Keeney D.R., Eds.), ASA, SSSA, Agronomy No: 9. Madison, Wisconsin, USA, ss. $199-224$.

Nelson D.W., Sommers L.E., (1982), Total carbon, organic carbon, and organic matter, Methods of Soil Analysis'in İçinde, Part 2, Chemical and Microbiological Properties (Page A.L., Miller R.H., Keeney D.R., Eds.), ASA, SSSA, Agronomy No: 9. Madison, Wisconsin, USA, ss. 539-579.

Nelson R.E., (1982), Carbonate and gypsum, Methods of Soil Analysis' in İçinde, Part 2, Chemical and Microbiological Properties (Page A.L., Miller R.H., Keeney D.R., Eds.), ASA, SSSA, Agronomy No: 9. Madison, Wisconsin, USA, ss. 181-197.

Nimmo J.R., Perkins K.S., (2002), Aggregate stability and size distribution, Methods of Soil Analysis'in İçinde, Part 4, Physical Methods (Dane J.H., Topp G.C., Eds.), SSSA Book Series 5. Madison, Wisconsin, USA, ss. 317-328.

Olsen S.R., Sommers L.E., (1982), Phosphorus, Methods of Soil Analysis'in İçinde, Part 2, Chemical and Microbiological Properties (Page A.L., Miller R.H., Keeney D.R., Eds.), ASA, SSSA, Agronomy No: 9. Madison, Wisconsin, USA, ss. 403-427.

Perinçek D., (2018), Çanakkale yöresi (KB Türkiye) Erenköy ve Güzelyalı fosil heyelanlarının jeolojik ve jeomorfolojik analizi, Türkiye Jeoloji Bülteni, 61(3), 241-268.

Reddy V.S., Singh J.S., (1992), Changes in soil properties and vegetation during postlandslide succession in pine forests of Central Himalaya, Oecologia Montana, 1(2), 33-42. 
Rhoades J.D., (1982), Soluble salts, Methods of Soil Analysis'in İçinde, Part 2, Chemical and Microbiological Properties (Page A.L., Miller R.H., Keeney D.R., Eds.), ASA, SSSA, Agronomy No: 9. Madison, Wisconsin, USA, ss. 167-179.

Schomakers J., Jien S.H., Lee T.S., Huang J.C., Hseu Z.Y., Lin Z.L., Lee L.C., Hein T., Mentler A., Zehetner F., (2017), Soil and biomass carbon re-accumulation after landslide disturbances, Geomorphology, 288, 164-174.

Simon N., Azlan N.N.N., Roslee R., Hussein A., Ern L.K., Sharir K., (2017), Physical soil characterization on stable and failed slopes of the Ranau-Tambunan road, Sabah, Malaysia, Nature Environment and Pollution Technology, 16(2), 659-665.

Sönmez İ., Kaplan M., Sönmez S., (2008), Kimyasal gübrelerin çevre kirliliği üzerine etkileri ve çözüm önerileri, Derim Dergisi, 25(2), 24-34.

URL-1, (2016), Çanakkale iklim verileri, Meteoroloji Genel Müdürlüğü, https://www.mgm.gov.tr/veridegerlendirme/il-ve-ilceleristatistik.aspx?m=CANAKKALE, [Erişim 16 Mayıs 2019].

Van Eynde E., Dondeyne S., Isabirye M., Deckers J., Poesen J., (2017), Impact of landslides on soil characteristics: Implications for estimating their age, Catena, 157, 173-179.

Walker L.R., Shiels A.R., (2012), Physical causes and consequences, Landslide Ecology'in İçinde (Walker L.R., Shiels A.R., Eds.), New York, Cambridge University Press. ss. 46-82.

Walker L.R., Zarin D.J., Fetcher N., Myster R.W., Johnson A.H., (1996), Ecosystem development and plant succession on landslides in the Caribbean. Biotropica, 28, 566-576.

Wilcke W., Valladarez H., Stoyan R., Yasin S., Valarezo C., Zech W., (2003), Soil properties on a chronosequence of landslides in montane rain forest, Ecuador, Catena, 53, 79-95.

Xu C., Sun Q., Yang X., (2018), A study of the factors influencing the occurrence of landslides in the Wushan area, Environmental Earth Sciences, doi: 10.1007/s12665-018-7584-2.

Yalçın A., (2011), A geotechnical study on the landslides in the Trabzon Province, NE, Turkey, Applied Clay Science, 52, 11-19.

Y1lmaz I., Karacan E,, (2002), A landslide in clayey soils: An examples from the Klzuldag region of the Sivas-Erzincan highway (Sivas-Turkey), Environmental Geosciences, 9(1), 35-42.

Yiğitbaş E., (2016), Jeolojik-antropojenik sebep sonuç ilişkileri açısından Çanakkale heyelanlarına toplu bakış, Çanakkale Heyelanları'nın İçinde, (Yiğitbaș E., Ed.), AFAD Çanakkale-Altın Kalemler, İzmir, ss. 9-25.

Zhang F., Chen W., Liu G., Liang S., Kang C., He F., (2012), Relationships between landslide types and topographic attributes in a Loess Catchment, China, Journal of Mountain Science, 9, 742-751. 